\title{
Effectiveness of simulation technique in teaching-learning process for prevention of postpartum hemorrhage in obstetrics and gynecology
}

\author{
Naina Kumar*, Swanand S. Pathak, Namit Kant Singh, Samar Rudra
}

Department of Obstetrics and Gynecology, Maharishi Markandeshwar Institute of Medical Sciences and Research, Mullana, Ambala, Haryana, India

Received: 18 June 2016

Accepted: 08 July 2016

\section{*Correspondence:}

Dr. Naina Kumar,

E-mail: drnainakumar@gmail.com

Copyright: (c) the author(s), publisher and licensee Medip Academy. This is an open-access article distributed under the terms of the Creative Commons Attribution Non-Commercial License, which permits unrestricted non-commercial use, distribution, and reproduction in any medium, provided the original work is properly cited.

\section{ABSTRACT}

Background: Simulation involves creation of artificial depiction of clinical situations which are rarely encountered. Objectives of the study to evaluate efficacy of simulation in teaching learning process for prevention of postpartum hemorrhage amongst postgraduates of Obstetrics Gynecology department.

Methods: Prospective study was conducted in Obstetrics Gynecology department of rural tertiary centre of Northern India over 6 months. Twenty one postgraduates of Obstetrics Gynecology department were randomly assigned to either simulation teaching using mannequin / didactic lecture on Active Management of Third Stage of Labor, ten students in each group (one dropped out). Efficacy of each teaching learning method was compared using multiple choice questionnaires: pre-teaching, post-teaching, Direct Observation of Procedural Skills (DOPS) encounter using structured checklist. Student satisfaction was evaluated using feedback questionnaire. Statistical analysis was done by Mann-Whitney test using SPSS-20 software.

Results: Both groups showed no difference in performance of pretest MCQ. Comparison of DOPS performance showed, significant difference $(\mathrm{p}=0.0003)$ between simulation and didactic lecture group (mean marks $5.20 \pm 0.79$ in Group 1 and 3.20 \pm 1.63 in Group 2). Both groups demonstrated significant improvement in post-teaching, but on comparison of post-test MCQ with pretest marks, significant difference was noted with mean difference of $7.80 \pm 1.76$ in Group 1, 3.60 \pm 1.98 in Group 2, with greater improvement observed among simulation group. Students ranked simulation higher with regard to enjoyment $(80 \%)$, interest $(75 \%)$, relevance $(75 \%)$, understanding $(70 \%)$ and accessibility to ask questions $(80 \%)$.

Conclusions: Simulation based teaching is better than didactic lecture as teaching learning modality especially for critical care procedures.

Keywords: Didactic lecture, Medical education, Postpartum hemorrhage, Simulation-based teaching, Teachinglearning modality

\section{INTRODUCTION}

Postpartum hemorrhage (PPH) is blood loss $>500 \mathrm{ml}$ following vaginal birth, $>1000 \mathrm{ml}$ following cesarean section. ${ }^{1}$ PPH is leading cause of maternal mortality, accounting for $25 \%$ of all maternal deaths, ${ }^{2}$ of which half occur in Africa and Asia. ${ }^{3}$ Its global prevalence is 6 to $11 \%{ }^{4,5}$ Deaths associated with PPH could be prevented with prompt recognition, timely, adequate management. ${ }^{6-}$
${ }^{8}$ Evidence suggests that active management of third stage of labor (AMTSL) reduces incidence, severity of PPH by 60 to $70 \%$. ' International Federation of Gynecology Obstetrics further state: "every attendant at birth should have knowledge, skills, judgment needed to carry AMTSL for preventing PPH". ${ }^{10}$ Hence, it is recommended that all delivering women should benefit from AMTSL. ${ }^{11}$ 
This is possible by training obstetric postgraduate students in preventing PPH. One such teaching modality is simulation using mannequin. Simulation is artificial creation of real process for training / performance testing. ${ }^{12}$ It is gaining popularity now-a-days and critical care teaching is best suited to simulation as it is impossible to demonstrate critical scenarios in real life. Furthermore with introduction of Work Place Based Assessment (WPBA), teaching, assessment can be done in single sitting. ${ }^{13}$ Direct Observation of Procedural Skills (DOPS) is form of WPBA used for evaluating procedural skills by observing students in workplace setting. ${ }^{14}$ Despite, clear evidence, observation of clinical work and feedback remains underutilized. Hence, this study was conducted with aim of training postgraduates of Obstetrics Gynecology department using newer modalities of teaching, assessment in performing AMTSL, so as to reduce incidence of PPH and maternal mortality. Aim of the study was to evaluate the efficacy of simulation technique in teaching-learning process for prevention of postpartum hemorrhage amongst postgraduate students of department of Obstetrics and Gynecology". Objectives of the study was to assess learning gains with and without simulation techniques using mannequin demonstration in prevention of $\mathrm{PPH}$, to assess performance of students in prevention of $\mathrm{PPH}$ using DOPS and to evaluate feedback regarding teaching with simulation techniques using mannequin for prevention of PPH in Obstetrics and Gynecology department of rural tertiary care centre of Northern India.

\section{METHODS}

Study type and study design: Prospective educational research study.

Place and duration of study: The present study was conducted in department of Obstetrics and Gynecology of a rural tertiary care centre of Northern India, after informed written consent from the students as well as patients and proper Institutional ethical approval over a period of six months.

Sample size: All 21 post-graduate students of Obstetrics and Gynecology department were enrolled in the study.

\section{Method of data collection}

First all 21 post-graduate students of Obstetrics and Gynecology department were made to solve a pretest on AMTSL, so as to have an idea about their basic knowledge about AMTSL and PPH prevention. Then they were randomly divided into 2 groups by chit system, so as to have equal number of first, second and third year students in each group. This was done by randomly asking each year resident to pick the chit with either group 1 or group 2 written over it. Group 1 was exposed to simulation based teaching using demonstration of all steps of AMTSL on mannequins along with basic knowledge and advantages of performing AMTSL in all delivering women and Group 2 was taught by traditional method of didactic lecture using chalk and board and power point presentations. Students in simulation group received hands-on exposure of performing the task on mannequins for 4 encounters each while Group 2 students received only verbal knowledge with no hands-on exposure for two months. After providing knowledge, both groups were then asked to perform on live delivering woman; steps of AMTSL. Assessment of all the students was then done using single encounter of DOPS structured checklist of total ten marks, so as to check the level of competency attained by students in both groups. Finally post-test was taken on AMTSL to judge their knowledge and skills attained by each teaching learning modality and to compare two methods of teaching. In second phase of study flipping of students was done, so that no student is deprived of either of the two modalities of teaching and also to remove bias. In last feedback forms were provided to every student to get their experiences about which teaching learning method was better and what all skills they have gained by performing same procedures on live patient under observation. They were also asked about various problems faced during their performance on live women and whether their competence has increased or not in performing these maneuvers in workplace.

\section{Measurements}

\section{Questionnaires and DOPS Structured checklist}

Comparison of efficacy of two teaching methods was done through pretest and post-test MCQ performance of 20 marks. Prior to teaching session either by simulation technique or by didactic lectures, each student completed baseline pretest questionnaire. After teaching, all the students were assessed at the workplace using DOPS structured checklist of 10 marks. Final assessment of all the students was then done using post-test MCQ of 20 marks. At the end of study all the students were given a feedback form to know which method of teaching was more beneficial for their knowledge as well as skill development.

\section{Statistical analysis}

Mann-Whitney test using SPSS 20 version software was used to evaluate results of pretest and post-test questionnaire and to compare performance of DOPS structured checklist in two groups. Analysis of feedback forms was done using five point Likert scale.

\section{RESULTS}

A total of 21 postgraduate students of Obstetrics and Gynecology department were enrolled in study. One student opted out due to health issues. Out of remaining 20 students, ten were randomized to simulation-based teaching, and ten to didactic lecture-based teaching on 
AMTSL. Both the groups showed no significant difference in baseline pretest MCQ marks (Table 1).

Table 1: Comparison of pretest and post-test MCQ Marks in two Groups.

\begin{tabular}{|lll|}
\hline AMTSL & $\begin{array}{l}\text { Pre-test MCQ } \\
\text { Result } \\
\text { Mean(+/-SD) }\end{array}$ & $\begin{array}{l}\text { Post-test MCQ } \\
\text { Result }\end{array}$ \\
\hline & $11.00 \pm 3.16$ & $18.80 \pm 1.40$ \\
\hline Simulation & $11.80 \pm 3.33$ & $15.40 \pm 1.35$ \\
\hline Didactic lecture & $\mathrm{P}=0.568$ & $\mathrm{P}=0.0003$ \\
\hline $\begin{array}{l}\text { Significance }(\mathbf{P} \\
\text { value) }\end{array}$ & & \\
\hline
\end{tabular}

Table 2: Comparison of student performance in DOPS encounter on AMTSL in two groups.

\begin{tabular}{|c|c|c|}
\hline Method of Teaching & DOPS 1 & $\mathrm{z}=\mathbf{3 . 6 0 5}$ \\
\hline Simulation $($ Mean \pm SD) & $5.20 \pm 0.79$ & $P=0.0003$ \\
\hline Didactic Lecture (Mean \pm SD) & $3.20 \pm 0.63$ & \\
\hline
\end{tabular}

After this the two groups were taught by two methods of teaching that is simulation based in Group 1 and Didactic lecture in Group 2 respectively. During their first DOPS checklist encounter of maximum10 marks; comparison of performance after simulation based teaching and performance after didactic lecture revealed statistically significant difference $(\mathrm{p}=0.0003)$ with mean marks achieved in Group 1: $5.20 \pm 0.79$ and Group 2: $3.20 \pm 1.63$ respectively (Table 2, Figure 1). On comparison of posttest and pretest MCQ marks, a significant difference was noted in each group with mean difference of $7.80 \pm 1.76$ in

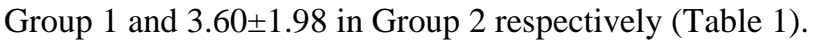

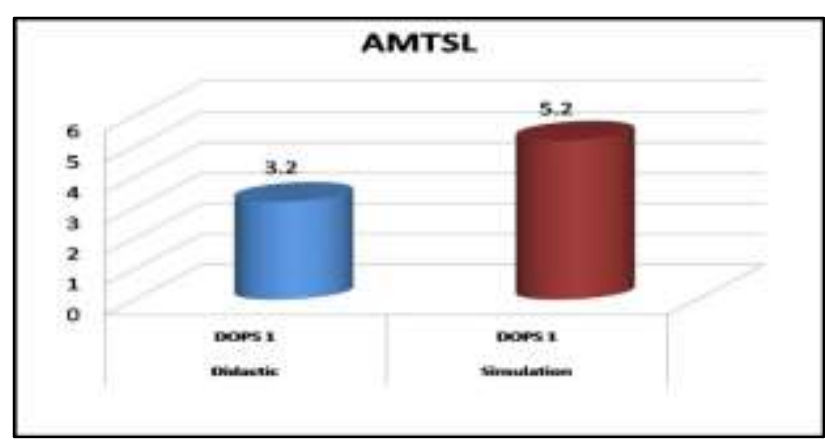

Figure 1: Comparison of mean values of student performance on DOPS encounter on AMTSL in two groups.

Table 3: Feedback survey results.

\begin{tabular}{|llllll|}
\hline $\begin{array}{l}\text { Teaching } \\
\text { Method }\end{array}$ & Enjoyment & Interest & Relevance & Understanding & Accessibility to posing questions \\
\hline Simulation & $80 \%(16 / 20)$ & $75 \%(15 / 20)$ & $75 \%(15 / 20)$ & $70 \%(14 / 20)$ & $80 \%(16 / 20)$ \\
\hline Didactic & $20 \%(4 / 20)$ & $25 \%(5 / 20)$ & $25 \%(5 / 20)$ & $30 \%(6 / 20)$ & $20 \%(4 / 20)$ \\
\hline
\end{tabular}

Scoring done on the basis of five point Likert scale 1: Strongly disagree; 2: Disagree; 3: Not sure; 4: Agree; 5: Strongly agree.

Also the students in simulation group performed better than didactic lecture group (Figures 2 and 3). Hence, it was observed that simulation based teaching resulted in better understanding of subject and performance on live patients as assessed by DOPS in comparison to didactic

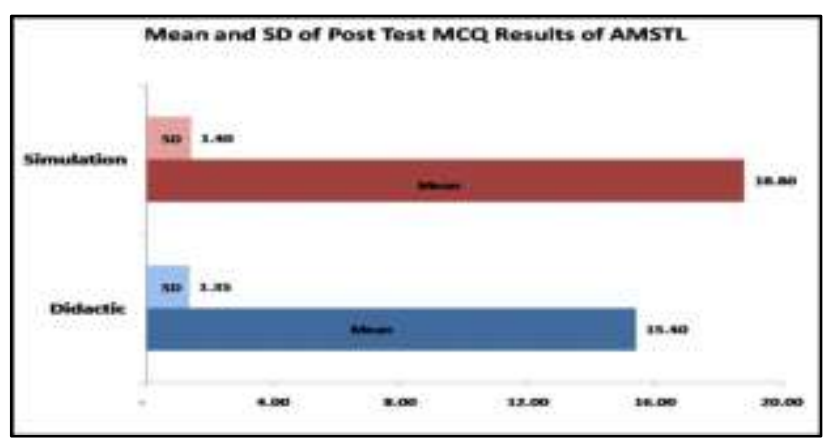

Figure 2: Comparison of mean and standard Deviation values of post-test MCQ marks on AMTSL two groups. lecture. Finally a qualitative analysis of feedback form results was done and students reported simulation-based teaching higher with regard to enjoyment, interest, relevance to subject taught, ease of understanding and accessibility to posing questions (Table 3 ).

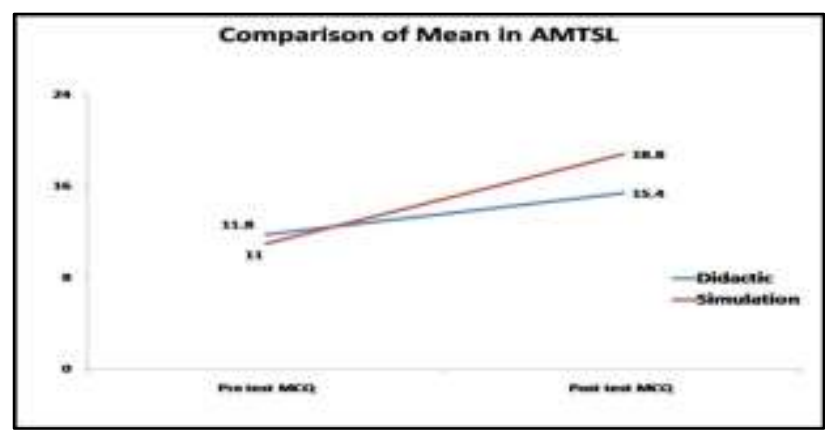

Figure 3: Comparison of mean values of pre-test and post-test MCQ marks in two groups. 


\section{DISCUSSION}

It would not be wrong to state that classroom teaching enables demonstrator to present factual material in logical manner to stimulate critical thinking among students, as eyes do not see what mind doesn't know. ${ }^{15}$ However, certain issues like one way communication, passive audience, and difficulty in assessing learning may act as limitations in classroom-based teaching. ${ }^{15}$ Also it was found that electronic teaching using power-point presentation may contribute toward passive learning and students can only retain information in short-term memory. ${ }^{16}$

Medical Education in this part of developing world is waking up to the reality that there is need for change from mostly knowledge-based education, to focus on skills that are needed to perform duties as health care professional. This has led to changes in medical education with emphasis shifting from teacher-centred to student-centred and from discipline-based to integrated learning to problem-based learning (health problems motivating students to learn what they need to know to solve problem to improve health) so that the health care provider is equipped with skills to enable them to solve real-life problems in hospital or community. ${ }^{17}$

In present study simulation based teaching learning method was compared with didactic lectures using DOPS as an assessment method and it was found that simulation based teaching resulted in better understanding of procedure. Also those students who were exposed to simulation based teaching using mannequins performed better on live patients in their DOPS encounter $(p=0.0003)$. Similar results were reported by a study comparing didactic lecture with use of simulation to teach peri-operative ultrasound which revealed higher test scores amongst simulation group. ${ }^{18}$

Another study also demonstrated significantly higher performance level in simulation group among residents and nurses being taught obstetrical emergencies compared to didactic teaching. ${ }^{19}$ Similarly a study demonstrated an improved task performance amongst students taught using simulation based learning, as compared to those learning by means of observed practice. $^{20}$

Another study compared simulation based learning with video assisted learning and found no significant differences in quantitative assessments between the two groups, although students found simulator sessions more enjoyable and valuable. ${ }^{21}$ Tan et al. demonstrated equal efficacy between simulation technique and conventional lecture in a group of students taught medical emergency management. $^{22}$ In our study also the simulation based teaching learning method was found to be more enjoyable and knowledgeable as compared to didactic lectures.
Furthermore in a study among Radiology trainees, Wang et al. $^{23}$ demonstrated no significant improvement in written test scores among trainees receiving didactic lecture versus simulation based training in management of contrast reaction, but performance among simulation based training was superior when tested in contrast reaction simulation scenario. Our study reported a significantly improved performance in post-teaching MCQ from baseline in simulation group compared to those who received didactic lecture $(18.80 \pm 1.40$ vs $15.40 \pm 1.35)$. Similar results were reported by a study comparing simulation based teaching with didactic lecture. $^{24}$

In the present study students were also asked to rate teaching experience at the end of study and it was found that statistically significant proportion of students favoured simulation-based teaching with regard to enjoyment, interest, relevance of subject chosen, understanding and posing questions. Similar results were obtained in other studies also, which reported that students enjoyed simulation based education more than didactic lectures. ${ }^{21,25}$ Studies thus far show that simulation based teaching in training medical students and residents are helpful in strengthening their skills, knowledge and also in evaluating their performance. ${ }^{26}$

\section{CONCLUSION}

The need for simulation-based medical education in clinical practice, especially in obstetrics and gynaecological critical care is likely to continue or increase due to proposed merits for both students and teachers. Also use of DOPS as an assessment and teaching tool is underutilized in obstetrics and gynaecology, so by using this WPBA tool we can help in overall improvement of skills, knowledge and attitude of students towards care of patient in real life situation.

There are some limitations of the studies listed here; Given that both simulation based teaching and DOPS are time and resource consuming, their long-term merits with regard to retaining knowledge and translating into improved patient care need to be further studied and confirmed in future, hence more studies with larger number of students can be done in future for better understanding of such teaching-learning and assessment methods for development of newer generation doctors.

\section{ACKNOWLEDGEMENT}

I acknowledge and thank Dr. Swanand S. Pathak for his constant guidance and advice for helping me in conducting this educational project. I also want to acknowledge the efforts of staff of department of Obstetrics and Gynecology of MMIMSR for their constant support and guidance. At last I want to thank my family for being my inspiration 
Funding: No funding sources

Conflict of interest: None declared

Ethical approval: The study was approved by the Institutional Ethics Committee

\section{REFERENCES}

1. Rath WH. Postpartum hemorrhage: update on problems of definitions and diagnosis. Acta Obstet Gynecol Scand. 2011;90(5):421-8.

2. World Health Organization, authors. Maternal mortality in 2005: estimates developed by WHO, UNICEF, UNFPA and the World Bank. Geneva (Switzerland): WHO; 2007.

3. Khan KS, Wojdyla D, Say L, Gulmezogh AM, Van Look PFA. WHO analysis of causes of maternal death: a systematic review. The Lancet 2006;367:1066-1074.

4. Carroli G, Cuesta C, Abalos E. Epidemiology of postpartum haemorrhage: a systematic review. Best Pract Res Clin Obstet Gynaecol. 2008;22(6):9991012.

5. Calvert C, Thomas SL, Ronsmans C. Identifying regional variation in the prevalence of postpartum haemorrhage: a systematic review and meta-analysis. PLoS One. 2012;7(7):e41114.

6. Berg CJ1, Harper MA, Atkinson SM, Bell EA, Brown HL, Hage ML, et al. Preventability of pregnancy-related deaths: results of a state-wide review. Obstet Gynecol. 2005;106(6):1228-34.

7. Kilpatrick SJ, Prentice P, Jones RL, Geller S. Reducing maternal deaths through state maternal mortality review. J Womens Health (Larchmt). 2012;21(9):905-9.

8. Della Torre M, Kilpatrick SJ, Hibbard JU, Simonson L, Scott S, Koch A, et al. Assessing preventability for obstetric hemorrhage. Am J Perinatol. 2011;28(10):753-60.

9. Prendiville WJ, Elbourne D, McDonald S. Active versus expectant management in the third stage of labour. Cochrane Database Syst Rev. 2000;(2):CD000007. Review. Update in: Cochrane Database Syst Rev. 2000;(3):CD000007.

10. International Confederation of Midwives, International Federation of Gynaecology and Obstetrics. Joint statement management of the third stage of labour to prevent postpartum haemorrhage. The Hague: ICM; London: FIGO; 2003. Available at:http://www.internationalmidwives.org/modules/C ontentExpress/img_repository/final\%20joint\%20stat ement\%20active\% 20 manangement-

eng\%20with\%20logo.pdf

or http://www.figo.org/content/PDF/PPH\%20Joint\%20 Statement.pdf. Accessed on October 12, 2006.

11. Kongnyuy EJ, Mlava G, van den Broek N. 'Using Criteria-Based Audit to Improve the Management of Postpartum Haemorrhage in Resource Limited Countries: a case study of malawi', Matern Child Health J. 2009;13(6):873-8.
12. Ogden PE, Cobbs LS, Howell MR, Sibbitt SJ, DiPette DJ. Clinical simulation: importance to the internal medicine educational mission. Am J Med. 2007;120(9):820-4.

13. Grenvik A, Schaefer JJ, DeVita MA, Rogers P. New aspects on critical care medicine training. Curr Opin Crit Care. 2004;10(4):233-7.

14. Wragg A, Wade W, Fuller G, Cowan G, Mills P. Assessing the performance of specialist registrars. Clin Med (Lond). 2003;3(2):131-4.

15. David C, Dianne D. The essential 20: twenty components of 237 an excellent health care team. Rose Dog Books. 2009:25-40.

16. Hossein N, Abdus S. The effect of power point presentations on student learning and attitudes. Global Perspect. Acc Educ. 2005;2:53-73.

17. Chacko TV. Moving toward competency-based education: Challenges and the way forward. Arch Med Health Sci. 2014;2:247-53. Available at: http://www.amhsjournal.org/text.asp?2014/2/2/247/1 44365 .

18. Ramsingh D, Alexander B, Le K, Williams W, Canales C, Cannesson M. Comparison of the didactic lecture with the simulation/model approach for the teaching of a novel perioperative ultrasound curriculum to anesthesiology residents. J Clin Anesth. 2014;26(6):443-54.

19. Daniels K, Arafeh J, Clark A, Waller S, Druzin M, Chueh J. Prospective randomized trial of simulation versus didactic teaching for obstetrical emergencies. Simul Healthc. 2010;5(1):40-5.

20. Hallikainen J, Väisänen $\mathrm{O}$, Randell $T$, Tarkkila $P$, Rosenberg PH, Niemi-Murola L. Teaching anaesthesia induction to medical students: comparison between full-scale simulation and supervised teaching in the operating theatre. Eur $\mathbf{J}$ Anaesthesiol. 2009;26(2):101-4.

21. Morgan PJ, Cleave-Hogg D, Mcllroy J, Devitt JH. Simulation technology: a comparison of experiential and visual learning for undergraduate medical students. Anesthesiology. 2002;96(1):10-6.

22. Tan GM, Ti LK, Tan K, Lee T. A comparison of screen-based simulation and conventional lectures for undergraduate teaching of crisis management. Anaesth Intensive Care. 2008;36(4):565-9.

23. Wang CL, Schopp JG, Petscavage JM, Paladin AM, Richardson ML, Bush WH. Prospective randomized comparison of standard didactic lecture versus highfidelity simulation for radiology resident contrast reaction management training. Am J Roentgenol. 2011;196(6):1288-95.

24. Solymos O, O'Kelly P, Walshe CM. Pilot study comparing simulation-based and didactic lecturebased critical care teaching for final-year medical students. BMC Anesthesiol. 2015;15:153.

25. Paskins Z, Peile E. Final year medical students' views on simulation-based teaching: a comparison with the best evidence medical education systematic review. Med Teach. 2010;32(7):569-77. 
26. Okuda Y, Bryson EO, DeMaria S Jr. The utility of simulation in medical education: what is the evidence? Mt Sinai J Med. 2009;76(4):330-43.
Cite this article as: Kumar N, Pathak SS, Singh NK, Rudra S. Effectiveness of simulation technique in teaching-learning process for prevention of postpartum hemorrhage in obstetrics and gynecology. Int J Reprod Contracept Obstet Gynecol 2016;5:2756-61. 